\title{
Journey from the Center of the Cell - the intra- and intercellular transport of mRNA
}

\author{
Anna Kasprowicz-Maluśki\#® ${ }^{\bowtie}$, Wojciech Kwiatkowski\#, Alicja Starosta and \\ Przemysław Wojtaszek
}

Department of Molecular and Cellular Biology, Adam Mickiewicz University, Poznań, Poland

\begin{abstract}
Transport and localized translation of mRNA is crucial for the proper spatiotemporal organization of proteins within cells. Distribution of RNAs to subcellular domains has recently emerged as a major mechanism for establishing functionally distinct compartments and structures in the cells. There is an emerging evidence that active transport of mRNA involves cytoskeleton and membrane trafficking pathways in fungi, plants and animals, suggesting that it is a common phenomenon among eukaryotes. The important highlights are that the RNA-binding proteins recognize the cargo mRNA and that RNPs are actively transported on the cytoskeletal tracks or co-transported with membranous compartments, such as the endoplasmic reticulum and endosomes. The interest of scientists has expanded over the past years in response to the discoveries that RNA can be exported from cells to play a role in the intercellular communication. In this review, we will focus on characterization of the RNA transport both, within a cell and between cells, and on the currently proposed mechanisms for RNA targeting.
\end{abstract}

Key words: RNP, extracellular RNA, localized RNA, cytoskeleton, extracellular vesicle (EV), multivesicular body (MVB)

Received: 06 June, 2016; revised: 13 July, 2016; accepted: 19 July, 2016; available on-line: 06 December, 2016

\section{INTRODUCTION}

Establishment of the cell polarity is crucial for the developmental processes, including specification of the cell fates, early embryonic patterning, cell movements and specialization of cell types. Cell polarization is determined by the asymmetric segregation of organelles and various macromolecules within the cell. Distribution of RNAs to subcellular domains has recently emerged as the major mechanism for establishing functionally distinct compartments and structures in the cells. Transport and localized translation of mRNA is crucial for the proper spatio-temporal organization of proteins within cells. To ensure the spatially restricted protein synthesis, translation of mRNAs is silenced during transport and activated once they reach the final destination. mRNA localization appears to be the rule, as $70 \%$ of about 2314 mRNAs tested in Drosophila melanogaster embryos exhibited a clearly defined localization pattern (Martin \& Ephrussi, 2009).

Transport of mRNAs to the destination domains is more suitable for a cell than transport of proteins. As a single RNA molecule can be used for translation of numerous proteins, the transport costs are reduced $(\mathrm{Me}-$ dioni et al., 2012). Transport of mRNAs can prevent proteins from acting ectopically before they reach the appropriate site and can facilitate incorporation of proteins into macromolecular complexes by generating high local protein concentrations and allowing co-translation of different subunits (Mingle et al., 2005). Nascent proteins may have properties distinct from the pre-existing copies due to post-translational modifications or chaperone-aided folding pathways (Dictenberg et al., 2008). mRNA targeting allows for fine-tuning of gene expression in both, space and time, e.g. different splice variants are targeted to distinct cellular compartments (Medioni et al., 2012; Baj et al., 2011).

Recent observations suggest that active mRNA targeting involves the cytoskeleton and membrane trafficking pathways in animals (Medioni et al., 2012), bacteria (Keiler, 2011), fungi (Zarnack \& Feldbrügge, 2010) and plants (Crofts et al., 2005), suggesting that it is a common phenomenon among eukaryotes. The inter- and intracellular transport pathways of RNA in eukaryotic cells are depicted in Fig. 1. Localization of mRNA molecules within the cytoplasm provides a basis for cell polarization, thus underlying developmental processes, such as asymmetric cell division, cell migration, neuronal maturation and embryonic patterning. Specific targeting of mRNAs in a cell can be achieved through different mechanisms. mRNA can be distributed due to (i) localized protection from degradation [e.g. D. melanogaster heat-shock protein-83 (Hsp83) mRNA (Aliotta et al., 2010; Ding et al., 1993)], (ii) passive diffusion coupled with local entrapment [e.g. D. melanogaster nanos mRNA (Forrest \& Gavis, 2003) and Xenopus laevis Xcat2 mRNA (Chang et al., 2004)] and (iii) finally mRNA can be actively transported to its destination domain (Besse \& Ephrussi, 2008). The latter pathway is the best one characterized and will be discussed within this review. Briefly, mRNA is recognized by RNA-binding proteins, which results in formation of

e-mail: akas@amu.edu.pl

\#These authors contributed equally to this work

Abbreviations: Ago, Argonaute protein; APC, adenomatous polyposis coli; CDS, coding sequence; CLIP-seq, ultraviolet in vivo RNAprotein cross-linking with immunoprecipitation and high-throughput sequencing; CRM1, Chromosomal Maintenance 1; DDX protein, DEAD-box protein; EJC, exon junction complex; ER, endosomal reticulum; ESCRT-II, Endosomal Sorting Complexes Required for Transport; EV, extracellular vesicle; exRNA, extracellular RNA; FMRP, Fragile X Mental Retardation Protein; hnRNP, heterogeneous nuclear RNP; Hsp83, heat-shock protein-83; mRNP, messenger ribonucleoprotein; MVB, multivesicular body; NPC, nuclear pore complex; NTP, nucleotide triphosphates; NXF1, nuclear export factor 1; NXT1, nuclear transport factor 2-like export factor 1; ORF, open reading frame; P bodies, processing bodies; RBP, RNA binding protein; RISC, RNA-induced silencing complex; RNP, ribonucleoprotein; SR protein, serine/arginine rich protein; TREX, three-prime repair exonuclease; UTR, untranslated region; Y RNA, small non-coding RNA 
mRNA-protein complexes that are transported within endomembrane system and/or along cytoskeletal tracks. RNA was once thought to exist in a stable form only inside the cells. However, recent research has indicated that RNAs can play a role not only in gene expression, but also in a variety of complex cellular functions. Extracellular RNA (exRNA) can be exported from cells in extracellular vesicles or bound to lipids or proteins, to play a role in intercellular communication. exRNA circulate through the tissues and affect cells at a great distance. What is important, a cell can accept exRNAs of heterologic origin, eg. absorbed from food, from microbes, or from the environment, potentially eliciting a variety of biological responses (Raposo \& Stoorvogel, 2013).

\section{OVERVIEW OF THE MRNA-PROTEIN COMPLEX}

Proteins form complexes with RNA (RNP - ribonucleoprotein) during transcription and participate in maturation of $\mathrm{mRNA}$, nuclear export (via the nuclear pore complex or budding through the nuclear envelope which applies to the extra-large mega RNPs), cellular transport and localization. They control where and when translation occurs, and determine the mode and rate of degradation if it does not happen (active messenger ribonucleoprotein (mRNP) dismantling is a prerequisite for efficient degradation) (Jansen et al., 2014; Singh et al., 2015).

Dynamic remodeling of mRNP composition takes place at each step of the mRNA transport. A crucial role in differentiating the composition and function of mRNP, play alternate 5' untranslated regions (UTRs), open reading frames (ORF), and 3' UTR sequences (Patzelt et al., 1983; Sonenberg et al., 1979). RNA binding proteins (RBPs) recognize structural elements, like $\mathrm{m}^{7} \mathrm{G}$ cap and poly A tail, or the sugar-phosphate backbone, or specific sequence motifs. They can also link up with secondary or tertiary structural elements in a sequence-independent way or simply follow the processing reactions (Kim \& Dreyfuss, 2001; Singh et al., 2015). Binding of some RBPs is conditioned by the concentration of small ligand molecules or intermediate metabolites (Hentze \& Preiss, 2010; Castello et al., 2015). There is also a class of proteins which link RNA with specificity for base modifications like N6-methyladenosine, 5-methylcytosine or pseudouridine (Carlile et al., 2014; Squires et al., 2012; Wang \& He, 2014). They are capable to modify bases, recognize modifications or remove them, and as a consequence modulate gene expression (Castello et al., 2012).

Assembling some RNPs can affect the remodeling of others which may lead to coupling numerous steps in the regulation of gene expression. The structure and composition of mRNPs play a role both, in contemporaneous and sequential coupling events (Moore \& Proudfoot, 2009). mRNPs are not confined to individual cellular compartments (Singh et al., 2015), as many of mRNPs formed in the nucleus may affect exploitation and metabolism in the cytoplasm (Cheng et al., 2006; Gebhardt et al., 2015; Merz et al., 2007; Moore \& Proudfoot, 2009). Prompt co-transcriptional mRNA packaging prevents hybridization of the newly transcribed RNA to the DNA strand within the transcription bubble - which may aid in maintaining the genome integrity (Paulsen et al., 2009). Formation of various mRNP and heterogeneous nuclear RNP (hnRNP) prevents hybridization of the emerging RNA with the unpaired template DNA, which could result in elongation defects, high rate of recombination, and general genomic instability (Domínguez-Sánchez et al., 2011; Li et al., 2007; Paulsen et al., 2009).

A model of distribution for mammalian RBPs alongside 5' UTRs, coding sequences (CDS), and 3' UTRs has been proposed (Singh et al., 2015). Based on the mRNAbinding data obtained e.g. by CLIP-seq (ultraviolet in vivo RNA-protein cross-linking with immunoprecipitation and high-throughput sequencing), it was suggested that the spliced mRNPs could be divided into three compositionally distinct domains. The 5' domain covers an area of the first exon which usually meets with the 5' UTR. This part is relatively protein free due to the ribosomelanding pad. The 3' domain includes the 3' UTR which is usually coincident with the last exon. In contrast to the opposite end, here one can find numerous RBPs, e.g. hnRNP proteins, as well as localization, translation, and decay factors. In mammalian mRNA, the CDS domain is usually rich with introns, and the protein coding region is abundant in EJCs (exon junction complex) and serine/arginine rich (SR) proteins. They are unequally distributed over ORFs, and 3' UTRs are specifically depleted in them. Besides them, there are also present translation regulators that influence the elongating ribosomes (Ji et al., 2016; Silverman et al., 2014).

After the RNP assembly, an important part in transport across the cell is the nuclear export. Correctly processed, and checked by a control mechanism, ribonucleoprotein particles move across the nucleoplasm (Percipalle et al., 2009). In the nuclei, mobility of RNP is limited by other particles and complexes, like nucleosomes, chromatin fibers and chromosomes in general. The accessibility of nuclear space, affected mostly by changes in the chromatin condensation, also changes during developmental states of the nuclei/cell (Wachsmuth et al., 2008). mRNPs are not actively transported within nucleoplasm, but by random Brownian motion (Oeffinger \& Zenklusen, 2012). It was shown that mRNP particles can diffuse in the nuclei with a similar speed as in the aqueous solution, and this is enabled by existing interchromatin channels. However, the diffusion not always occurs with the maximum speed, and sometimes the particles can be retarded due to some processing events. Also, some large molecular non-chromatin structures in the nuclei can inhibit the mobility of mRNPs, which moreover can interact with these structures (Veith et al., 2010). Transport of RNA through NPC (nuclear pore complex) is actively supported by proteins that make up the mRNP complex (Visa et al., 1996). All three mRNP domains are modified even during the nuclear transport. Export receptor, the NXF1-NXT1 heterodimer, mediates the NPC transit. In the nucleus, NXF1 and NXT1 are connected by multiple adaptors, such as the TREX components, the SR proteins, the DDX (DEAD-box) protein Dbp5 or cleavage and polyadenylation specificity factor 6. Sites of recruitment occur in all three mRNP domains, so probably a single mRNP combines with various NXF1NXT1 molecules (Silverman et al., 2014). The main role in the mRNP translocation from the nuclei is played by Dpb5, an ATP-dependent RNA helicase, which is involved in remodeling of the mRNP. After changing conformation of the particle, $\mathrm{mRNP}$ is not be able to reenter the nuclei across NPC. That important step occurs at the external site of a nuclear membrane (Siebrasse et al., 2012) and it could be valid to make the transport more efficient and also to control the export of special mRNP cohorts (also known as regulons, groups of mRNAs jointly controlled by one or more RBPs) (Keene, 2007; Valencia et al., 2008). Moreover, thanks to the export adaptors, mRNPs can transit through the 
NPC in several orientations (Singh et al., 2015). This applies to mRNAs which have no need to release the 5', end first into the cytoplasm to bind ribosomes just during the transit through the pore but are sequestered away from the ribosomes until they reach their suitable subcellular target (Daneholt, 2001). Another export pathway uses the karyopherin CRM1 instead of NXF1 (Brennan et al., 2000). The protein factors responsible for budding ultralarge mRNPs via the nuclear envelope are still unknown (Speese et al., 2012). Average mRNPs, during the transport through the central NPC channel, may require only minimal remodeling (Batisse et al., 2009), in contrast to especially large mRNPs which need to undergo severe remodeling events, like unfolding, to transit through the pores (Skoglund et al., 1983).

After mRNAs get into the cytoplasm, they must be deprived of export receptor proteins to prevent their return. Proteins taking part in this process have been described, however, the exact mechanical details of how it works still require an explanation (Carmody \& Wente, 2009; Valkov et al., 2012). The way of exchange of nuclear components for the cytoplasmic ones depends on their interaction strength. Passive or active remodeling is possible. Passive remodeling occurs due to mass action and is taking place only after stochastic dissociation of the weakly bound nuclear components. This frees up binding sites for proteins whose abundance is far higher in the cytoplasm (Fritzsche et al., 2013; Maquat et al., 2010). Active remodeling requires an energy input, usually obtained by hydrolysis of the nucleotide triphosphates (NTP). Such hydrolysis occurs during scanning of the small (40S) subunit along the 5' UTR and translocation of $80 \mathrm{~S}$ ribosomes through the ORF. The first round of translation can start the active remodeling (Gehring et al., 2009; Huang et al., 2004).

Probably, most of the mRNPs are exported through NPC as singletons (Park et al., 2014). Nevertheless, group complexes appear in the cells as well. In the brain tissue extremely large assemblies with multiple mRNA molecules were detected (Krichevsky \& Kosik, 2001). Besides neuronal granules, other large cytoplasmic mRNA aggregations were also discovered, like processing bodies ( $\mathrm{P}$ bodies), stress granules or germ granules. High amounts of RNA degradation factors in the P bodies suggest that mRNA degradation may take place there (Anderson \& Kedersha, 2006). Stress granules are formed temporarily in response to adverse conditions. Their function is to protect mRNAs and relieve ribosomes, so that they are able to synthesize proteins specific to stress, while the germ granules are unique to germlines (Voronina et al., 2011). Still, referring to the just mentioned $\mathrm{P}$ bodies and the degradation process, final disassembling still leaves a lot of questions and unsolved issues. The proteins must be finally removed so that the degradative enzymes have an access to mRNA. Half-life of mRNPs is usually set between a few minutes to more than 24 hours. Accumulation of mRNA decay intermediates decreases cell fitness (Schoenberg \& Maquat, 2012). RBPs in the 5' UTR region are not stably bound and RBPs located in CDS are removed during ribosome transit, while 3' UTR is the hardest part to disassemble (Kurosaki \& Maquat, 2016).

After successful export of mRNP from the nuclei, there are a few ways to deliver these particles to the destination site. During movement across the nuclear pore, there may occur changes in their conformation, which can affect the mRNA accessibility for the ribosomes. This is a direct, but not a common way, to get a given
mRNA to be expressed (Percipalle et al., 2009). There are another ways to deliver mRNPs to the cellular periphery, where mRNA can be translated, and protein synthesis can be done. mRNP is assembled in specific structures, which helps the ribonucleoprotein particles to move to their destination, known as RNA granules. These big macromolecular complexes consist of factors necessary for active and correct transport, such as conventional kinesin and cytoplasmic dynein. Also, they contain some subunits to facilitate translation - ribosomal subunits, aminoacyl-tRNA synthases and elongation factors. After a proper assembly of this complex, the RNA granules can be assigned to specific cytoplasmic compartments, which may depend on the cell type, stage of the cell life and also on the type of mRNA cargo (Percipalle et al., 2009).

A classical way of RNP trafficking depends on the type of RNA which is being transported - is the RNA going to be translated or not. In correct subcellular delivery of a given RNA, the key role plays a zipcode - a cis-acting RNA sequence element, which is recognized by specific trans-acting localization factors (Cohen, 2005).

\section{SUBCELLULAR TARGETING OF MRNA}

The distance of mRNA transport can be very long, especially in highly polarized cells, e.g. neurons. The existence of special transport pathways would improve the efficiency of mRNA delivery and determine the precise spatiotemporal localization of mRNAs, regulation of translation and subsequent protein production in correct subcellular domains. To reach its subcellular destination, mRNA must be first recognized by trans-acting factors and form the mRNP complex that is involved in recruitment of the motor proteins. Then, the mRNA cargo is transported on the cytoskeletal tracks to the final location (Fig. 1). The active transport takes place both, in targeting of uniformly distributed transcripts and localizing mRNAs (Fusco et al., 2003; Bullock et al., 2006a). Both: microtubules, associated with such motor proteins as kinesins and/or dyneins, and actin filaments, associated with such motor proteins as myosins, can be involved in mRNA transport in a cell- and an mRNA-type dependent manner (St Johnston, 2005; Böhl et al., 2000; MacDougall et al., 2003; Wilkie \& Davis, 2001).

The type and number of active molecular motors recruited to a target mRNA implicate the choice of the cytoskeletal tracks (actin filaments or microtubules) used for the mRNA transport, the type of movement (uni- or bidirectional), and the properties (e.g. speed, processivity) of mRNA transport (Gagnon \& Mowry, 2011; Marchand et al., 2012; Medioni et al., 2012). The RNA-binding proteins are controlling the kinetics of mRNA transport by limiting the number of motor proteins bound to mRNP and the balance between these motors (Bullock et al., 2006a, 2006b). It has been confirmed that e.g. yeast ASH1 mRNA is transported by actin, whereas $D$. melanogaster oskar mRNA and $X$. laevis $\mathrm{Vg} 1 \mathrm{mRNA}$ are transported by tubulin. Yeast mutants that prevent bundling of actin cables have been shown to result in mislocalization of ASH1 mRNA (Takizawa et al., 1997). The efficiency of monodirectional ASH1 mRNA transport on actin filaments in yeast is enhanced by the recruitment of several molecules of the myosin motor (Chung \& Takizawa, 2010). Due to the recruitment of opposite acting motors, RNPs transported in dendrites exhibit a microtubule-dependent bidirectional movement (Doyle \& Kiebler, 2011). The RBP FMRP binds to transcripts transported in 


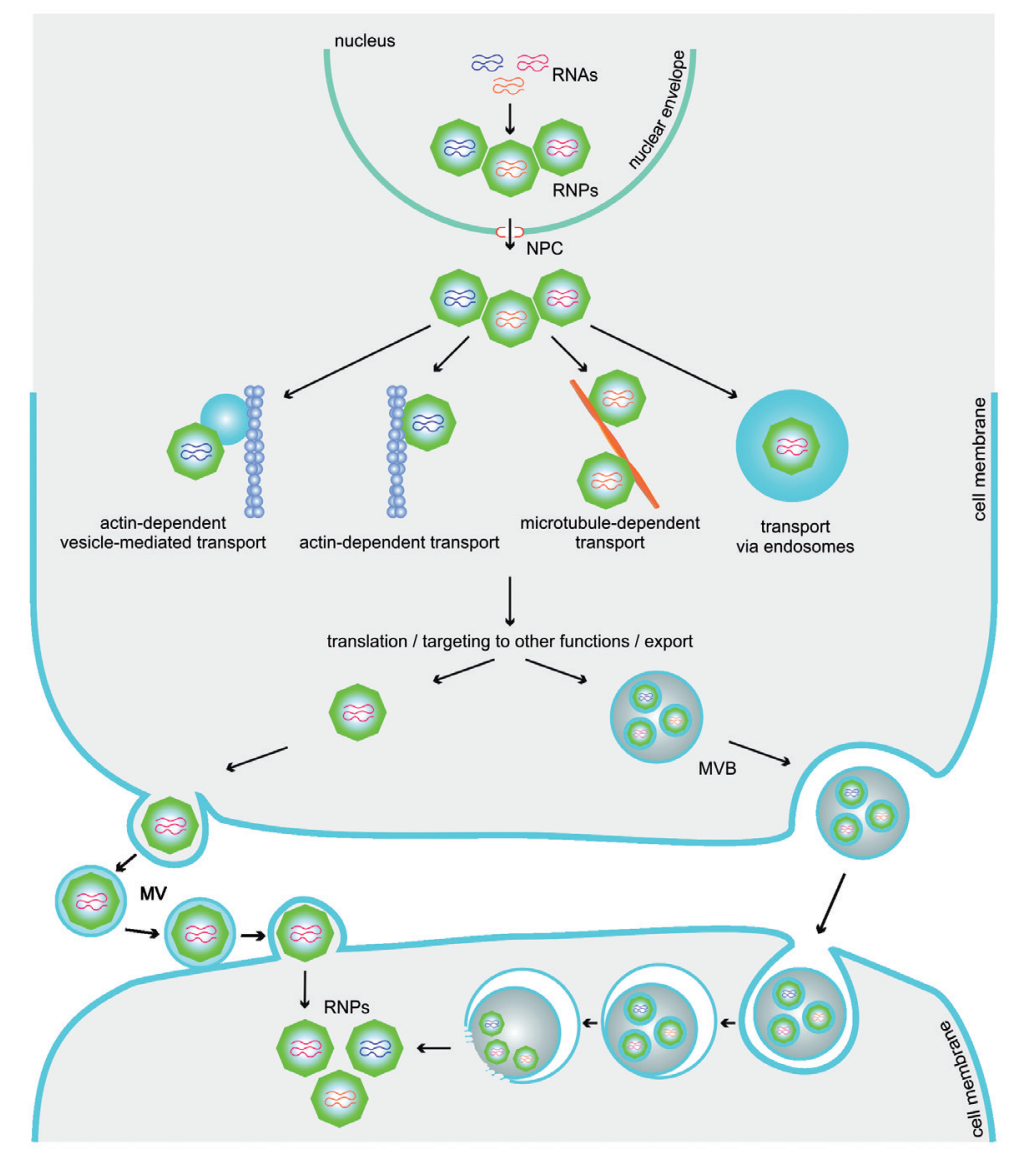

Figure 1. Schematic of the RNA transfer in eukaryotic cells. RNAs form complexes with proteins (RNPs) that are exported from the nucleus to the cytoplasm through NPC.

RNA cargo can be delivered to the destination domain on cytoskeletal tracks (actin or tubulin) or can be selectively incorporated into the MVBs or MVs budding from the plasma membrane. MVBs fuse with the plasma membrane releasing exosomes into the extracellular environment. MVs and exosomes may bind to the plasma membrane of a target cell and fuse directly with the plasma membrane or may be endocytosed. As a result, the RNA is delivered into the cytoplasm of the target cell.

dendrites, and also to a component of the plus-end motor Kinesin-1 and to the dynein-interacting BicD protein (Dictenberg et al., 2008; Bianco et al., 2013). This would allow RNPs to ensure a constant reassessment and finetuning of the directional transport (Medioni et al., 2012).

When mRNAs reach their final destination, they must be stably retained at this subcellular domain. Generally, the anchorage of mRNA is controlled by actin, actin binding proteins and the motor proteins (Delanoue \& Davis, 2005). In recent years, alternative actin-independent mechanisms have been discovered (Medioni et al., 2012): in mammalian migrating cells accumulation of transcripts in protrusions depends on the tumor-suppressor APC (Mili et al., 2008); in D. melanogaster blastoderm embryos apical anchoring of pair-rule transcripts requires a motor activity-independent function of dynein (Delanoue \& Davis, 2005), and in ascidian eggs transcripts are associated with a sub-domain of the cortical ER (endoplasmic reticulum) (Paix et al., 2011). In some cells, no static anchor is pre-localized and subcellular targeting of mRNA can be achieved via continuous rounds of short-range active transport, as shown for bicoid mRNA localization at the anterior pole of the late-stage $D$. melanogaster oocytes (Weil et al., 2006).

There is an emerging evidence that localized transport of mRNA is related to membrane trafficking. The im- portant highlights are that the RNAbinding proteins recognize the cargo mRNA synergistically and that $\mathrm{mR}$ NAs are co-transported with membranous compartments, such as the (ER) and endosomes. The novel concept of endosome-coupled translation that loads shuttling endosomes with a septin cargo was studied in a fungal model system (Jansen et al., 2014). In Sachcaromyces cerevisiae, the core factors of the mRNA SHE trafficking machinery include the myosin motor Myo4p, the adaptor protein She3p, and the RNAbinding protein She2p (Heym \& Niessing, 2012). This machinery transports approximately 30 types of transcripts along actin tracks from the mother cell to the tip of the budding daughter cell during cell division and polar growth (Hermesh \& Jansen, 2013). This mechanism allows for accumulation of mRNA at the growth pole of the daughter cells, resulting in a specific subcellular localized expression in the bud. It was proven that She2p is both, an RNA an lipid-binding protein, with preference to bind to membranes of high curvature, as e.g. ER, and that it interacts more strongly with ER than with other membranes (Genz et al., 2013). An RNA live imaging confirmed that the co-transport of mRNA and ER is dependent on the SHE machinery in S. cerevisiae (Schmid et al., 2006). Most of the mRNAs transported in an ER-dependent manner encode proteins translated at the ER membrane and secreted proteins or proteins required for establishment of polarized secretion (Fundakowski et al., 2012)

In filamentous fungi, e.g. Ustilago maydis, the polar extension at the hyphal growth pole depends on effective vesicular transport on microtubule tracks (Riquelme, 2013). mRNAs encoding mainly the membrane-associated proteins shuttle on dynamic endosomes and constitute a pathway for long-distance membrane and mRNA trafficking (Koepke et al., 2011). The RBP Rrm4-mRNA complex that is important for hyphal growth, was found in endosomes shuttling along microtubules in the endosomal motors Kin3- and Dyn1/2-dependent manner (Zarnack \& Feldbrügge, 2010; Baumann et al., 2012). There is a hypothesis that mRNPs may shuttle bidirectionally on moving endosomes in order to distribute mRNAs and ribosomes, as well as to deliver the translated products (Jansen et al., 2014). An emerging evidence is accumulating that the RNA and membrane trafficking is also tightly interwoven in higher eukaryotes, suggesting that this is a common phenomenon. In D. melanogaster oocytes, oskar mRNA-containing RNPs are transported along microtubules with a random orientation. Mammalian neurons exhibit extensive shuttling of mRNPs but without significant accumulation at specific subcellular sites (Zimyanin et al., 2008). Genomic RNA of HIV-1 is transported on endosomes and Endosomal Sorting Complexes Required for Transport (ESCRT-II) components are crucial for trafficking (Ghoujal et al., 2012; Molle et al., 2009). Membrane trafficking also seems to be in- 
volved in RNA silencing in plants and animals (Kim et al., 2014). The RNA-induced silencing complex (RISC) controls stability and translation of target mRNAs. RISC is mainly formed by Argonaute (Ago) proteins and small RNAs (small interfering RNAs or microRNAs). Ago was identified as a membrane-associated protein with unknown function, GERp95 (Golgi-ER p95) (Kim et al., 2014). It was discovered that Ago and small RNAs associate with the ER, Golgi, endosomes, multivesicular bodies (MVBs), autophagosomes, and secretory vesicles (Kim et al., 2014). In animal cells, an active RISC is assembled at the cytoplasmic part of the ER (Stalder et al., 2013), and in plants, an ER-associated RISC regulates translation of target mRNAs (Li et al., 2013).

\section{INTERCELLULAR TARGETING OF RNA}

The exchange of extracellular vesicles carrying a protein and an RNA cargo seems to be an evolutionarily conserved mechanism of cell-cell communication (Ratajczak et al., 2006; Valadi et al., 2007). A classical secretory pathway addresses the release of ER-Golgi transported proteins into the extracellular space. Recent observations suggest that secretion of the proteins/RNA through extracellular vesicles (EVs) may serve as an important pathway in the cell development and communication (Rodrigues et al., 2008; Meyer et al., 2009). The major categories of cell membrane-derived vesicles are currently distinguished on the basis of size, density, and characteristic marker protein expression, and are divided into exosomes and ectosomes (Keerthikumar et al., 2015; Samuel et al., 2015). Exosomes are secreted microvesicles (30-150 nm in diameter) of endocytic origin that are conserved across various species and cell types (Lötvall et al., 2014; Gangoda et al., 2015). Exosomes are released into the extracellular space via exocytosis after fusion of the MVB with the plasma membrane (Cocucci et al., 2009; Simons \& Raposo, 2009). Ectosomes or shedding microvesicles are generally larger (100-1000 $\mathrm{nm}$ in diameter), and bud off directly from the plasma membrane (Keerthikumar et al., 2015). The budding of microvesicles involves cortical actin reorganization followed by the outward protrusion of plasma membrane domains and subsequent detachment. There is a growing evidence of vesicular transport of RNA. A wide range of RNA species, including mRNA, was detected in the vesicles (Roberts \& Kurre, 2013). Analysis of RNA from EVs (extracellular vesicle) by unbiased deep sequencing approaches demonstrated that, in addition to mRNA and miRNA, EVs also contain a large variety of other small noncoding RNA species, including RNA transcripts overlapping with protein coding regions, repeat sequences, structural RNAs, tRNA fragments, vault RNA, Y RNA, and small interfering RNAs (Bellingham et al., 2012; Nolte-'t Hoen et al., 2012). The ExoCarta database (http://www.exocarta.org) and the Vesiclepedia compendium (http://microvesicles.org/index.html) index the RNA and other molecules that have been identified in the EVs from different sources (Raposo \& Stoorvogel, 2013). The RNAs are selectively incorporated into EVs, as it was found that many RNAs that were isolated with EVs were enriched relative to the RNA profiles of the originating cells (Ratajczak et al., 2006; Valadi et al., 2007; Skog et al., 2008; Nolte-'t Hoen et al., 2012). RNAs in EVs share specific sequence motifs that may potentially function as cisacting elements for targeting to EVs (Batagov et al., 2011). Evidence that MVBs are sites of miRNA-loaded RISC accumulation (Gibbings et al., 2009), and that exosome-like vesicles are considerably enriched in GW182 and AGO2, implicate functional roles of these proteins in the RNA sorting to exosomes (Raposo \& Stoorvogel, 2013). The $\mathrm{EV}$ function in physiological and pathological processes depends on their ability to interact with the recipient cells to deliver their cargo. Target cell specificity for EV binding is probably determined by adhesion molecules, such as integrins, that are present in the EVs. While bound to the recipient cells, EVs may remain stably associated with the plasma membrane or dissociate, directly fuse with the plasma membrane, or be internalized through distinct endocytic pathways (Fig.1). When endocytosed, EVs may subsequently fuse with the endosomal membrane or be targeted to the lysosomes for degradation (Raposo \& Stoorvogel, 2013). Vesicle trafficking that involves direct cell-cell delivery of RNA may influence the transcriptional control of cellular programs in the target cell. Vesicle trafficking may have a far-reaching effect as the cytoplasmic exchange of RNA or protein might reprogram the cells, alter tissue-specific gene expression, and modulate the cell fates (Ratajczak et al., 2006; Aliotta et al., 2010).

\section{Acknowledgements}

This work was supported by the KNOW RNA Research Centre in Poznań (No. 01/KNOW2/2014).

\section{REFERENCES}

Aliotta JM, Pereira M, Johnson KW, de Paz N, Dooner MS, Puente N, Ayala C, Brilliant K, Berz D, Lee D, Ramratnam B, McMillan PN, Hixson DC, Josic D, Quesenberry PJ (2010) Microvesicle entry into marrow cells mediates tissue-specific changes in mRNA by direct delivery of mRNA and induction of transcription. Exp Hematol 38: 233-245. http://doi.org/10.1016/j.exphem.2010.01.002

Anderson P, Kedersha N (2006) RNA granules. J Cell Biol 172: 803808. http://doi.org/10.1083/jcb.200512082

Baj G, Leone E, Chao M V, Tongiorgi E (2011) Spatial segregation of BDNF transcripts enables BDNF to differentially shape distinct dendritic compartments. Proc Natl Acad Sci U S A 108: 1681316818. http://doi.org/10.1073/pnas.1014168108

Batagov AO, Kuznetsov VA, Kurochkin I V (2011) Identification of nucleotide patterns enriched in secreted RNAs as putative cis-acting elements targeting them to exosome nano-vesicles. BMC Genomics 12 (Suppl 3): S18. http://doi.org/10.1186/1471-2164-12-S3-S18

Batisse J, Batisse C, Budd A, Böttcher B, Hurt E (2009) Purification of nuclear poly(A)-binding protein $\mathrm{Nab} 2$ reveals association with the yeast transcriptome and a messenger ribonucleoprotein core structure. J Biol Chem 284: 34911-34917. http://doi.org/10.1074/jbc. M109.062034

Baumann S, Pohlmann T, Jungbluth M, Brachmann A, Feldbrügge M (2012) Kinesin-3 and dynein mediate microtubule-dependent cotransport of mRNPs and endosomes. J Cell Sci 125: 2740-2752. http://doi.org/10.1242/jcs.101212

Bellingham SA, Coleman BM, Hill AF (2012) Small RNA deep sequencing reveals a distinct miRNA signature released in exosomes from prion-infected neuronal cells. Nucleic Acids Res 40: $10937-$ 10949. http://doi.org/10.1093/nar/gks832

Besse F, Ephrussi A (2008) Translational control of localized mRNAs: restricting protein synthesis in space and time. Nat Rev Mol Cell Biol 9: 971-980. http://doi.org/10.1038/nrm2548

Bianco P, Cao X, Frenette PS, Mao JJ, Robey PG, Simmons PJ, Wang C-Y (2013) The meaning, the sense and the significance: translating the science of mesenchymal stem cells into medicine. Nat Med 19: 35-42. http://doi.org/10.1038/nm.3028

Böhl F, Kruse C, Frank A, Ferring D, Jansen RP (2000) She2p, a novel RNA-binding protein tethers ASH1 mRNA to the Myo4p myosin motor via She3p. EMBO J 19: 5514-5524. http://doi.org/10.1093/ emboj/19.20.5514

Brennan CM, Gallouzi IE, Steitz JA (2000) Protein ligands to HuR modulate its interaction with target mRNAs in vivo. J Cell Biol 151: 1-13. http://doi.org/10.1083/jcb.151.1.1

Bullock SL, Nicol A, Gross SP, Zicha D (2006a) Guidance of bidirectional motor complexes by mRNA cargoes through control of dynein number and activity. Curr Biol 16: 1447-1452. http://doi. org/10.1016/j.cub.2006.05.055

Bullock SL, Nicol A, Gross SP, Zicha D (2006b) Guidance of bidirectional motor complexes by mRNA cargoes through control of dynein number and activity. Curr Biol 16: 1447-1452. http://doi. org/10.1016/j.cub.2006.05.055 
Carlile TM, Rojas-Duran MF, Zinshteyn B, Shin H, Bartoli KM, Gilbert W V (2014) Pseudouridine profiling reveals regulated mRNA pseudouridylation in yeast and human cells. Nature 515: 143-146. http://doi.org/10.1038/nature13802

Carmody SR, Wente SR (2009) mRNA nuclear export at a glance. $J$ Cell Sci 122: 1933-1937. http://doi.org/10.1242/jcs.041236

Castello A, Fischer B, Eichelbaum K, Horos R, Beckmann BM, Strein C, Davey NE, Humphreys DT, Preiss T, Steinmetz LM, Krijgsveld J, Hentze MW (2012) Insights into RNA biology from an atlas of mammalian mRNA-binding proteins. Cell 149: 1393-1406. http:// doi.org/10.1016/j.cell.2012.04.031

Castello A, Hentze MW, Preiss T (2015) Metabolic enzymes enjoying new partnerships as RNA-binding proteins. Trends Endocrinol Metab 26: 746-757. http://doi.org/10.1016/j.tem.2015.09.012

Chang P, Torres J, Lewis RA, Mowry KL, Houliston E, King M Lou (2004) Localization of RNAs to the mitochondrial cloud in Xenopus oocytes through entrapment and association with endoplasmic reticulum. Mol Biol Cell 15: 4669-4681. http://doi.org/10.1091/mbc. E04-03-0265

Cheng H, Dufu K, Lee C-S, Hsu JL, Dias A, Reed R (2006) Human mRNA export machinery recruited to the 5' end of mRNA. Cell 127: 1389-400. http://doi.org/10.1016/j.cell.2006.10.044

Chung S, Takizawa PA (2010) Multiple Myo4 motors enhance ASH1 mRNA transport in Saccharomyces cerevisiae. J Cell Biol 189: 755-767. http://doi.org/10.1083/jcb.200912011

Cocucci E, Racchetti G, Meldolesi J (2009) Shedding microvesicles: artefacts no more. Trends Cell Biol 19: 43-51. http://doi.org/10.1016/j. tcb.2008.11.003

Cohen RS (2005) The role of membranes and membrane trafficking in RNA localization. Biol Cell 97: 5-18. http://doi.org/10.1042/ BC20040056

Crofts AJ, Washida H, Okita TW, Satoh M, Ogawa M, Kumamaru T, Satoh H (2005) The role of mRNA and protein sorting in seed storage protein synthesis, transport, and deposition. Biochem Cell Biol 83: 728-737. http://doi.org/10.1139/o05-156

Daneholt B (2001) Packing and delivery of a genetic message. Chromosoma 110: 173-85

Delanoue R, Davis I (2005) Dynein anchors its mRNA cargo after apical transport in the Drosophila blastoderm embryo. Cell 122: 97106. http://doi.org/10.1016/j.cell.2005.04.033

Dictenberg JB, Swanger SA, Antar LN, Singer RH, Bassell GJ (2008) A direct role for FMRP in activity-dependent dendritic mRNA transport links filopodial-spine morphogenesis to fragile $\mathrm{X}$ syndrome. Dev Cell 14: 926-939. http://doi.org/10.1016/j.devcel.2008.04.003

Ding D, Parkhurst SM, Halsell SR, Lipshitz HD (1993) Dynamic Hsp83 RNA localization during Drosophila oogenesis and embryogenesis. Mol Cell Biol 13: 3773-3781

Domínguez-Sánchez MS, Barroso S, Gómez-González B, Luna R, Aguilera A (2011) Genome instability and transcription elongation impairment in human cells depleted of THO/TREX. PLoS Genet 7: e1002386. http://doi.org/10.1371/journal.pgen.1002386

Doyle M, Kiebler MA (2011) Mechanisms of dendritic mRNA transport and its role in synaptic tagging. EMBO J 30: 3540-3552. http://doi.org/10.1038/emboj.2011.278

Forrest KM, Gavis ER (2003) Live imaging of endogenous RNA reveals a diffusion and entrapment mechanism for nanos mRNA localization in Drosophila. Curr Biol 13: 1159-1168

Fritzsche R, Karra D, Bennett KL, Ang FY, Heraud-Farlow JE, Tolino M, Doyle M, Bauer KE, Thomas S, Planyavsky M, Arn E, Bakosova A, Jungwirth K, Hörmann A, Palfi Z, Sandholzer J, Schwarz M, Macchi P, Colinge J, Superti-Furga G, Kiebler MA (2013) Interactome of two diverse RNA granules links mRNA localization to translational repression in neurons. Cell Rep 5: 1749-1762. http:// doi.org/10.1016/j.celrep.2013.11.023

Fundakowski J, Hermesh O, Jansen R-P (2012) Localization of a subset of yeast mRNAs depends on inheritance of endoplasmic reticulum. Traffic 13: 1642-1652. http://doi.org/10.1111/tra.12011

Fusco D, Accornero N, Lavoie B, Shenoy SM, Blanchard JM, Singer RH, Bertrand E (2003) Single mRNA molecules demonstrate probabilistic movement in living mammalian cells. Curr Biol 13: 161-167

Gagnon JA, Mowry KL (2011) Molecular motors: directing traffic during RNA localization. Crit Rev Biochem Mol Biol 46: 229-239. http:// doi.org/10.3109/10409238.2011.572861

Gangoda L, Boukouris S, Liem M, Kalra H, Mathivanan S (2015) Extracellular vesicles including exosomes are mediators of signal transduction: are they protective or pathogenic? Proteomics 15: 260-271. http://doi.org/10.1002/pmic.201400234

Gebhardt A, Habjan M, Benda C, Meiler A, Haas DA, Hein MY, Mann A, Mann M, Habermann B, Pichlmair A (2015) mRNA export through an additional cap-binding complex consisting of NCBP1 and NCBP3. Nat Commun 6: 8192. http://doi.org/10.1038/ ncomms 9192

Gehring NH, Lamprinaki S, Kulozik AE, Hentze MW (2009) Disassembly of exon junction complexes by PYM. Cell 137: 536-548. http://doi.org/10.1016/j.cell.2009.02.042
Genz C, Fundakowski J, Hermesh O, Schmid M, Jansen R-P (2013) Association of the yeast RNA-binding protein She2p with the tubular endoplasmic reticulum depends on membrane curvature. J Biol Chem 288: 32384-32393. http://doi.org/10.1074/ibc.M113.486431

Ghoujal B, Milev MP, Ajamian L, Abel K, Mouland AJ (2012) ESCRTII's involvement in HIV-1 genomic RNA trafficking and assembly. Biol Cell 104: 706-721. http://doi.org/10.1111/boc.201200021

Gibbings DJ, Ciaudo C, Erhardt M, Voinnet O (2009) Multivesicular bodies associate with components of miRNA effector complexes and modulate miRNA activity. Nat Cell Biol 11: 1143-1149. http:// doi.org/10.1038/ncb1929

Hentze MW, Preiss T (2010) The REM phase of gene regulation. Trends Biochem Sci 35: 423-426. http://doi.org/10.1016/j.tibs.2010.05.009

Hermesh O, Jansen R-P (2013) Take the (RN)A-train: localization of mRNA to the endoplasmic reticulum. Biochim Biophys Acta 1833: 2519-2525. http://doi.org/10.1016/j.bbamcr.2013.01.013

Heym RG, Niessing D (2012) Principles of mRNA transport in yeast. Cell Mol Life Sci 69: 1843-1853. http://doi.org/10.1007/s00018-0110902-4

Huang Y, Yario TA, Steitz JA (2004) A molecular link between SR protein dephosphorylation and mRNA export. Proc Natl Acad Sci U S A 101: 9666-96670. http://doi.org/10.1073/pnas.0403533101

Jansen R-P, Niessing D, Baumann S, Feldbrügge M (2014) mRNA transport meets membrane traffic. Trends Genet 30: 408-417. http:// doi.org/10.1016/j.tig.2014.07.002

Ji Z, Song R, Huang H, Regev A, Struhl K (2016) Transcriptome-scale RNase-footprinting of RNA-protein complexes. Nat Biotechnol 34: 410-413. http://doi.org/10.1038/nbt.3441

Keene JD (2007) RNA regulons: coordination of post-transcriptional events. Nat Rev Genet 8: 533-543. http://doi.org/10.1038/nrg2111

Keerthikumar S, Gangoda L, Liem M, Fonseka P, Atukorala I, Ozcitti C, Mechler A, Adda CG, Ang C-S, Mathivanan S (2015) Proteogenomic analysis reveals exosomes are more oncogenic than ectosomes. Oncotarget 6: 15375-15396. http://doi.org/10.18632/oncotarget.3801

Keiler KC (2011) RNA localization in bacteria. Curr Opin Microbiol 14: 155-159. http://doi.org/10.1016/j.mib.2011.01.009

Kim VN, Dreyfuss G (2001) Nuclear mRNA binding proteins couple pre-mRNA splicing and post-splicing events. Mol Cells 12: 1-10

Kim YJ, Maizel A, Chen X (2014) Traffic into silence: endomembranes and post-transcriptional RNA silencing. EMBO J 33: 968-980. http://doi.org/10.1002/embj.201387262

Koepke J, Kaffarnik F, Haag C, Zarnack K, Luscombe NM, König J, Ule J, Kellner R, Begerow D, Feldbrügge M (2011) The RNA-binding protein Rrm4 is essential for efficient secretion of endochitinase Cts1. Mol Cell Proteomics 10: M111.011213. http://doi.org/10.1074/ mcp.M111.011213

Krichevsky AM, Kosik KS (2001) Neuronal RNA granules: a link between RNA localization and stimulation-dependent translation. Neuron 32: 683-696. http://doi.org/10.1016/S0896-6273(01)00508-6

Kurosaki T, Maquat LE (2016) Nonsense-mediated mRNA decay in humans at a glance. J Cell Sci 129: 461-467. http://doi.org/10.1242/ jcs. 181008

Li S, Liu L, Zhuang X, Yu Y, Liu X, Cui X, Ji L, Pan Z, Cao X, Mo B, Zhang F, Raikhel N, Jiang L, Chen X (2013) MicroRNAs inhibit the translation of target mRNAs on the endoplasmic reticulum in Arabidopsis. Cell 153: 562-574. http://doi.org/10.1016/j. cell.2013.04.005

Li X, Niu T, Manley JL (2007) The RNA binding protein RNPS1 alleviates ASF/SF2 depletion-induced genomic instability. RNA 13: 2108-2115. http://doi.org/10.1261/rna.734407

Lötvall J, Hill AF, Hochberg F, Buzás EI, Vizio D Di, Gardiner C, Gho YS, Kurochkin I V., Mathivanan S, Quesenberry P, Sahoo S, Tahara H, Wauben MH, Witwer KW, Théry C (2014) Minimal experimental requirements for definition of extracellular vesicles and their functions: a position statement from the International Society for Extracellular Vesicles. I Extracell Vesicles 3

MacDougall N, Clark A, MacDougall E, Davis I (2003) Drosophila gurken $(\mathrm{TGF} \alpha) \mathrm{mRNA}$ Localizes as particles that move within the oocyte in two dynein-dependent steps. Dev Cell 4: 307-319. http:// doi.org/10.1016/S1534-5807(03)00058-3

Maquat LE, Hwang J, Sato H, Tang Y (2010) CBP80-promoted mRNP rearrangements during the pioneer round of translation, nonsense-mediated mRNA decay, and thereafter. Cold Spring Harb Symp Quant Biol 75: 127-134. http://doi.org/10.1101/sqb.2010.75.028

Marchand V, Gaspar I, Ephrussi A (2012) An intracellular transmission control protocol: assembly and transport of ribonucleoprotein complexes. Curr Opin Cell Biol 24: 202-210. http://doi.org/10.1016/j. ceb.2011.12.014

Martin KC, Ephrussi A (2009) mRNA localization: gene expression in the spatial dimension. Cell 136: 719-730. http://doi.org/10.1016/j. cell.2009.01.044

Medioni C, Mowry K, Besse F (2012) Principles and roles of mRNA localization in animal development. Development 139: 3263-3276. http://doi.org/10.1242/dev.078626 
Merz C, Urlaub H, Will CL, Lührmann R (2007) Protein composition of human mRNPs spliced in vitro and differential requirements for mRNP protein recruitment. $R N A$ 13: 116-128. http://doi. org $/ 10.1261 /$ rna.336807

Meyer D, Pajonk S, Micali C, O’Connell R, Schulze-Lefert P (2009) Extracellular transport and integration of plant secretory proteins into pathogen-induced cell wall compartments. Plant J 57: 986-999. http://doi.org/10.1111/j.1365-313X.2008.03743.x

Mili S, Moissoglu K, Macara IG (2008) Genome-wide screen reveals APC-associated RNAs enriched in cell protrusions. Nature 453: 115-119. http://doi.org/10.1038/nature06888

Mingle LA, Okuhama NN, Shi J, Singer RH, Condeelis J, Liu G (2005) Localization of all seven messenger RNAs for the actin-polymerization nucleator Arp $2 / 3$ complex in the protrusions of fibroblasts. I Cell Sci 118: 2425-2433. http://doi.org/10.1242/jcs.02371

Molle D, Segura-Morales C, Camus G, Berlioz-Torrent C, Kjems J, Basyuk E, Bertrand E (2009) Endosomal trafficking of HIV-1 gag and genomic RNAs regulates viral egress. J Biol Chem 284: $19727-$ 19743. http://doi.org/10.1074/jbc.M109.019844

Moore MJ, Proudfoot NJ (2009) Pre-mRNA Processing reaches back totranscription and ahead to translation. Cell 136: 688-700. http:// doi.org/10.1016/j.cell.2009.02.001

Nolte-'t Hoen ENM, Buermans HPJ, Waasdorp M, Stoorvogel W, Wauben MHM, 't Hoen PAC (2012) Deep sequencing of RNA' from immune cell-derived vesicles uncovers the selective incorporation of small non-coding RNA biotypes with potential regulatory functions. Nucleic Acids Res 40: 9272-9285. http://doi.org/10.1093/ nar/gks658

Oeffinger M, Zenklusen D (2012) To the pore and through the pore: A story of mRNA export kinetics. Biochim Biophys Acta-Gene Regul Mech 1819: 494-506. http://doi.org/10.1016/j.bbagrm.2012.02.011

Paix A, Le Nguyen PN, Sardet C (2011) Bi-polarized translation of ascidian maternal mRNA determinant pem-1 associated with regulators of the translation machinery on cortical Endoplasmic Reticulum (cER). Dev Biol 357: 211-226. http://doi.org/10.1016/j. ydbio.2011.06.019

Park HY, Lim H, Yoon YJ, Follenzi A, Nwokafor C, Lopez-Jones M, Meng X, Singer RH (2014). Visualization of dynamics of single endogenous mRNA labeled in live mouse. Science 343: 422-424. http://doi.org/10.1126/science.1239200

Patzelt E, Blaas D, Kuechler E (1983) CAP binding proteins associated with the nucleus. Nucleic Acids Res 11: 5821-5835

Paulsen RD, Soni D V, Wollman R, Hahn AT, Yee M, Guan A, Hesley JA, Miller SC, Cromwell EF, Solow-Cordero DE, Meyer T, Cimprich KA (2009) A genome-wide siRNA screen reveals diverse cellular processes and pathways that mediate genome stability. Mol Cell 35: 228-239. http://doi.org/10.1016/j.molcel.2009.06.021

Percipalle P, Raju CS, Fukuda N (2009) Actin-associated hnRNP proteins as transacting factors in the control of mRNA transport and localization. RNA Biol 6: 171-174. http://doi.org/10.4161/ rna.6.2.8195

Raposo G, Stoorvogel W (2013) Extracellular vesicles: exosomes, microvesicles, and friends. I Cell Biol 200: 373-383. http://doi. org/10.1083/jcb.201211138

Ratajczak J, Miekus K, Kucia M, Zhang J, Reca R, Dvorak P, Ratajczak MZ (2006) Embryonic stem cell-derived microvesicles reprogram hematopoietic progenitors: evidence for horizontal transfer of mRNA and protein delivery. Leukemia 20: 847-856. http://doi. org $/ 10.1038 /$ sj.leu. 2404132

Riquelme M (2013) Tip growth in filamentous fungi: a road trip to the apex. Annu Rev Microbiol 67: 587-609. http://doi.org/10.1146/ annurev-micro-092412-155652

Roberts CT, Kurre P (2013) Vesicle trafficking and RNA transfer add complexity and connectivity to cell-cell communication. Cancer Res 73: 3200-3205. http://doi.org/10.1158/0008-5472.CAN-13-0265

Rodrigues ML, Nimrichter L, Oliveira DL, Nosanchuk JD, Casadevall A (2008) Vesicular trans-cell wall transport in fungi: a mechanism for the delivery of virulence-associated macromolecules? Lipid Insights 2: $27-40$

Samuel M, Bleackley M, Anderson M, Mathivanan S (2015) Extracellular vesicles including exosomes in cross kingdom regulation: a viewpoint from plant-fungal interactions. Front Plant Sci 6: 1-5. http:// doi.org/10.3389/fpls.2015.00766

Schmid M, Jaedicke A, Du T-G, Jansen R-P (2006) Coordination of endoplasmic reticulum and mRNA localization to the yeast bud. Curr Biol 16: 1538-1543. http://doi.org/10.1016/j.cub.2006.06.025

Schoenberg DR, Maquat LE (2012) Regulation of cytoplasmic mRNA decay. Nat Rev Genet 13: 246-259. http://doi.org/10.1038/nrg3160

Siebrasse JP, Kaminski T, Kubitscheck U (2012) Nuclear export of single native mRNA molecules observed by light sheet fluorescence microscopy. Proc Natl Acad Sci U S A 109: 9426-9431. http://doi. org/10.1073/pnas.1201781109

Silverman IM, Li F, Alexander A, Goff L, Trapnell C, Rinn JL, Gregory BD (2014) RNase-mediated protein footprint sequencing reveals protein-binding sites throughout the human transcriptome. Genome Biol 15: R3. http://doi.org/10.1186/gb-2014-15-1-r3
Simons M, Raposo G (2009) Exosomes - vesicular carriers for intercellular communication. Curr Opin Cell Biol 21: 575-581. http://doi. org/10.1016/j.ceb.2009.03.007

Singh G, Pratt G, Yeo GW, Moore MJ (2015) The Clothes Make the mRNA: Past and Present Trends in mRNP Fashion. Annu Rev Biochem 84: 325-354. http://doi.org/10.1146/annurev-biochem-080111-092106

Skog J, Würdinger T, van Rijn S, Meijer DH, Gainche L, Sena-Esteves M, Curry W'T, Carter BS, Krichevsky AM, Breakefield XO (2008) Glioblastoma microvesicles transport RNA and proteins that promote tumour growth and provide diagnostic biomarkers. Nat Cell Biol 10: 1470-1476. http://doi.org/10.1038/ncb1800

Skoglund U, Andersson K, Björkroth B, Lamb MM, Daneholt B (1983) Visualization of the formation and transport of a specific hnRNP particle. Cell 34: 847-855

Sonenberg N, Rupprecht KM, Hecht SM, Shatkin AJ (1979) Eukaryotic mRNA cap binding protein: purification by affinity chromatography on sepharose-coupled m7GDP. Proc Natl Acad Sci U S A 76: 4345-4349. http://doi.org/10.1073/pnas.76.9.4345

Speese SD, Ashley J, Jokhi V, Nunnari J, Barria R, Li Y, Ataman B, Koon A, Chang Y-T, Li Q, Moore MJ, Budnik V (2012) Nuclear envelope budding enables large ribonucleoprotein particle export during synaptic Wnt signaling. Cell 149: 832-846. http://doi. org/10.1016/j.cell.2012.03.032

Squires JE, Patel HR, Nousch M, Sibbritt T, Humphreys DT, Parker BJ, Suter CM, Preiss T (2012) Widespread occurrence of 5-methylcytosine in human coding and non-coding RNA. Nucleic Acids Res 40: 5023-5033. http://doi.org/10.1093/nar/gks144

St Johnston D (2005) Moving messages: the intracellular localization of mRNAs. Nat Rev Mol Cell Biol 6: 363-375. http://doi.org/10.1038/ nrm1643

Stalder L, Heusermann W, Sokol L, Trojer D, Wirz J, Hean J, Fritzsche A, Aeschimann F, Pfanzagl V, Basselet P, Weiler J, Hintersteiner M, Morrissey D V, Meisner-Kober NC (2013) The rough endoplasmatic reticulum is a central nucleation site of siRNA-mediated RNA silencing. EMBO J 32: 1115-1127. http://doi.org/10.1038/ emboj.2013.52

Takizawa PA, Sil A, Swedlow JR, Herskowitz I, Vale RD (1997) Actindependent localization of an RNA encoding a cell-fate determinant in yeast. Nature 389: 90-93. http://doi.org/10.1038/38015

Valadi H, Ekström K, Bossios A, Sjöstrand M, Lee JJ, Lötvall JO (2007) Exosome-mediated transfer of mRNAs and microRNAs is a novel mechanism of genetic exchange between cells. Nat Cell Biol 9: 654-659. http://doi.org/10.1038/ncb1596

Valencia P, Dias AP, Reed R (2008) Splicing promotes rapid and efficient mRNA export in mammalian cells. Proc Natl Acad Sci U S A 105: 3386-3391. http://doi.org/10.1073/pnas.0800250105

Valkov E, Dean JC, Jani D, Kuhlmann SI, Stewart M (2012) Structural basis for the assembly and disassembly of mRNA nuclear export complexes. Biochim Biophys Acta 1819: 578-592. http://doi. org/10.1016/j.bbagrm.2012.02.017

Veith R, Sorkalla T, Baumgart E, Anzt J, Häberlein H, Tyagi S, Siebrasse JP, Kubitscheck U (2010) Balbiani ring mRNPs diffuse through and bind to clusters of large intranuclear molecular structures. Biopbys J 99: 2676-2685. http://doi.org/10.1016/j. bpj.2010.08.004

Visa N, Alzhanova-Ericsson AT, Sun X, Kiseleva E, Björkroth B, Wurtz T, Daneholt B (1996) A Pre-mRNA-binding protein accompanies the RNA from the gene through the nuclear pores and into polysomes. Cell 84: 253-264. http://doi.org/10.1016/S00928674(00)80980-0

Voronina E, Seydoux G, Sassone-Corsi P, Nagamori I (2011) RNA Granules in Germ Cells. Cold Spring Harb Perspect Biol 3: a002774a002774. http://doi.org/10.1101/cshperspect.a002774

Wachsmuth M, Caudron-Herger M, Rippe K (2008) Genome organization: Balancing stability and plasticity. Biochim Biophys Acta - Mol Cell Res 1783: 2061-2079. http://doi.org/10.1016/j.bbamcr.2008.07.022

Wang X, He C (2014) Reading RNA methylation codes through methyl-specific binding proteins. RNA Biol 11: 669-672. http://doi. org/dx.doi.org/10.4161/rna.28829

Weil TT, Forrest KM, Gavis ER (2006) Localization of bicoid mRNA in late oocytes is maintained by continual active transport. Dev Cell 11: 251-262. http://doi.org/10.1016/j.devcel.2006.06.006

Wilkie GS, Davis I (2001) Drosophila wingless and Pair-Rule Transcripts Localize Apically by Dynein-Mediated Transport of RNA Particles. Cell 105: 209-219. http://doi.org/10.1016/S00928674(01)00312-9

Zarnack K, Feldbrügge M (2010) Microtubule-dependent mRNA transport in fungi. Eukaryot Cell 9: 982-990. http://doi.org/10.1128/ EC.00030-10

Zimyanin VL, Belaya K, Pecreaux J, Gilchrist MJ, Clark A, Davis I, St Johnston D (2008) In vivo imaging of oskar mRNA transport reveals the mechanism of posterior localization. Cell 134: 843-853. http:// doi.org/10.1016/j.cell.2008.06.053 